Article

\title{
Amniotic Fluid Arginine from Gestational Weeks 13 to 15 Is a Predictor of Birth Weight, Length, and Head Circumference
}

\author{
Astrid Bjørke-Jenssen ${ }^{1}$, Per Magne Ueland ${ }^{2,3}$ and Anne-Lise Bjørke-Monsen ${ }^{2, *}$ \\ 1 Faculty of Medicine and Health Sciences, Norwegian University of Science and Technology, \\ 7491 Trondheim, Norway; astridbjenssen@gmail.com \\ 2 Laboratory of Clinical Biochemistry, Haukeland University Hospital, 5021 Bergen, Norway; \\ Per.Ueland@k2.uib.no \\ 3 Institute of Medicine, University of Bergen, 5021 Bergen, Norway \\ * Correspondence: almo@helse-bergen.no; Tel.: +47-5597-5000
}

Received: 6 November 2017; Accepted: 12 December 2017; Published: 14 December 2017

\begin{abstract}
Arginine is a constituent of proteins and a precursor for polyamines and nitric oxide, and is essential for placentation, angiogenesis, and growth. Maternal plasma arginine concentrations are found to be lower in pregnancies complicated by fetal growth restriction, and arginine supplementation in later pregnancy is reported to increase birth weight. We measured arginine and the metabolites asymmetric dimethylarginine (ADMA) and symmetric dimethylarginine (SDMA) in the amniotic fluid obtained in pregnancy weeks 13 to 15 from 363 pregnancies with a documented normal outcome and related the concentrations to birth weight, length, and head circumference. Arginine was higher in the amniotic fluid from female (mean 40.8 (SD 10.6) $\mu \mathrm{mol} / \mathrm{L}$ ) compared to male fetuses (37.4 (SD 11.2) $\mu \mathrm{mol} / \mathrm{L}, p=0.003$ ). Despite the gender difference, arginine in the amniotic fluid from gestational weeks 13-15 was the strongest predictor for birth weight, length, and head circumference. ADMA was a strong predictor for birth weight and length, SDMA for birth weight, while Arg/ADMA and Arg/SDMA only predicted head circumference in multiple linear regression models. Due to increased arginine demands, pregnancy is considered a state of relative arginine deficiency. Our findings reflect the importance of a good maternal arginine status in early pregnancy, an observation that should be evaluated in an intervention study.
\end{abstract}

Keywords: amino acids; arginine; fetal growth; pregnancy; placentation

\section{Introduction}

Arginine plays an essential role in fetal and placental development and is reported to be abundant in the amniotic fluid in early pregnancy [1-3] Arginine serves as a building block of proteins and a key regulator of several metabolic pathways [4]. Arginine is hydrolyzed to ornithine and converted into the polyamines putrescine, spermine, and spermidine [5], key regulators of placental angiogenesis, trophoblast growth, and embryogenesis [6].

Arginine is additionally the substrate for the production of nitrix oxide (NO), and asymmetric dimethylarginine (ADMA), a guanindine $\left(N^{G}\right)$-dimethylated derivate of arginine, is a strong direct inhibitor of nitric oxide synthase (NOS). Symmetric dimethylarginine (SDMA) is an indirect and weaker inhibitor of NOS and a marker of renal function. The ratio Arg/ADMA is considered to be a marker of NOS activity [7], and a low ratio is regarded as a marker of endothelial dysfunction [8]. Pregnancy is associated with enhanced vasodilatation, and NO has been assigned a particular role in the physiological vascular adaptation [9] that is considered to be essential for the formation of a healthy endothelium and for promoting the endovascular invasion by the cytotrophoblast [10]. 
Due to the increased needs for arginine for placental and fetal growth [11], pregnancy is considered to be a state of relative arginine deficiency [12]. Maternal plasma arginine concentrations were found to be lower in pregnancies complicated by fetal growth restriction [13,14].

Before keratinization of the fetal skin occurs around gestational week 20, the composition of the amniotic fluid is considered to reflect the metabolite profile of fetal plasma and provides a rational compartment for studies of fetal nutrition and metabolism [1].

We have measured arginine and the metabolites ADMA and SDMA in amniotic fluid obtained in pregnancy weeks 13 to 15 from pregnancies with a documented normal outcome. The aim of the study was to evaluate the relation between these amino acids and the final birth weight, length, and head circumference.

\section{Materials and Methods}

Samples of amniotic fluid taken by transabdominal amniocentesis for genetic prenatal diagnosis at Haukeland University Hospital, Bergen, Norway, during 1995 through 1998 were eligible for this observational study. The gestational age was determined by menstrual dates and checked by ultrasound examination. The information about pregnancy outcomes was collected from questionnaires routinely returned after delivery. Samples from singleton pregnancies with a documented normal outcome, obtained at gestational weeks 13, 14, and 15 were included in the study $(n=371)$. Birth before gestational week 37 was defined as premature birth, and a birth weight below 2500 grams at term was defined as small for gestational age (SGA).

The samples were stripped for identifiers, the procedures for information collection were in accordance with the revised Helsinki declaration of 1983, and the study was granted approval by the Regional Committee on Medical Research Ethics West (365/02).

\subsection{Sampling and Biochemical Analysis}

The samples were centrifuged after amniocentesis and stored at $-20{ }^{\circ} \mathrm{C}$ until analyses were done in 1999. Amniotic fluid concentrations of arginine, ADMA, and SDMA were measured using a LC-MS/MS method [15] by the laboratory Bevital AS, Bergen Norway (www.bevital.no).

\subsection{Statistical Analysis}

Data are presented as mean and SD and compared by ANOVA test, or as median and interquartile range (IQR) and compared by Kruskal-Wallis test. Multiple linear regression models, corrected for gender, gestational age at sampling, and storage period were used to explore the relationships between amniotic fluid arginine, ADMA, or SDMA concentrations and growth parameters at birth (weight, length, and head circumference). Graphical illustrations of the relationships between arginine or the methylarginines and birth weight were obtained by generalized additive models (GAM), corrected for gender, gestational age at sampling, and storage period.

The SPSS statistical program (version 23) and the package "mgcv" in $R$, version 3.3 (The $R$ Foundation for Statistical Computing, Vienna, Austria) were used for the statistical analyses. Two-sided $p$-Values $<0.05$ were considered statistically significant.

\section{Results}

\subsection{Characteristics of the Study Population}

The main indication for amniocentesis was maternal age (Table 1$)$. The infants were healthy and born at term with an appropriate weight for gestational age, apart from three infants $(0.8 \%)$ who were born premature and six term-born infants $(1.6 \%)$ who were defined SGA. These nine infants were excluded, thereby leaving amniotic fluid from 363 pregnancies with a documented normal outcome eligible for the study. 
The mean birth weight was higher in boys compared to girls (3713 (SD 562) versus 3592 (SD 468) $\mathrm{g}, p=0.03$ ), and the same pattern was seen for birth length (50.8 (SD 2.8) versus 49.9 (SD 2.4) cm, $p=0.005$ ) and head circumference (35.7 (SD 1.4) versus 35.2 (SD 1.5), cm, $p=0.008$ ).

Table 1. Characteristics of the population $(n=363)$.

\begin{tabular}{cc}
\hline Indications for Amniocentesis & \\
\hline Maternal age $>38$ years, $n(\%)$ & $315(87)$ \\
Previous child with chromosomal aberration or malformation, $n(\%)$ & $31(8)$ \\
Maternal epilepsy, $n(\%)$ & $6(2)$ \\
Other, $n$ (\%) & $11(3)$ \\
Maternal age, years, median (total range) & $39.0(24.0-45.0)$ \\
Gestational age, week, median (total range) & $14.0(13.0-15.0)$ \\
Male sex, $n(\%)$ & $180(50)$ \\
Birth weight, g, mean (SD) & $3650(520)$ \\
Birth length, cm, mean (SD) & $50.3(2.6)$ \\
Head circumference, cm, mean (SD) & $35.5(1.4)$ \\
Apgar score 1, mean (SD) & $9(1)$ \\
Apgar score 2, mean (SD) & $9(1)$ \\
\hline
\end{tabular}

\subsection{Arginine and Metabolite Concentrations According to Gestational Age}

The mean arginine $(-13 \%)$, ADMA $(-15 \%)$, and SDMA $(-10 \%)$ concentrations decreased significantly from gestational week 13 to 15, while no such trend was seen for the ratios Arg/ADMA and Arg/SDMA (Table 2). The storage time varied from 1 to 4 years, with no difference according to the gestational week at sampling $(p=0.41)$.

Table 2. Concentrations of arginine, asymmetric dimethylarginine (ADMA), and symmetric dimethylarginine (SDMA) in amniotic fluid $(n=363)$ according to the pregnancy week.

\begin{tabular}{ccccc}
\hline \multirow{2}{*}{ Parameters } & \multicolumn{3}{c}{ Pregnancy Week } & \multirow{2}{*}{$\boldsymbol{p}$-Value } \\
\cline { 2 - 4 } & $\mathbf{1 3}(\boldsymbol{n = 1 1 0 )}$ & $\mathbf{1 4}(\boldsymbol{n}=\mathbf{2 1 7})$ & $\mathbf{1 5}(\boldsymbol{n}=\mathbf{3 6})$ & \\
\hline Sampling year & $1996(1995-1997)$ & $1996(1995-1997)$ & $1996(1995-1996)$ & $0.26^{*}$ \\
\hline Arginine, $\mu \mathrm{mol} / \mathrm{L}$ & $41.3(11.4)$ & $38.4(11.1)$ & $36.0(8.3)$ & $0.019^{* *}$ \\
\hline Asymmetric dimethylarginine, $\mu \mathrm{mol} / \mathrm{L}$ & $2.71(0.52)$ & $2.66(0.49)$ & $2.28(0.38)$ & $<0.001^{* *}$ \\
\hline Symmetric dimethylarginine, $\mu \mathrm{mol} / \mathrm{L}$ & $1.59(0.34)$ & $1.59(0.33)$ & $1.41(0.31)$ & $0.008^{* *}$ \\
\hline Arg/ADMA & $15.2(3.3)$ & $14.5(3.4)$ & $16.1(4.0)$ & $0.015^{* *}$ \\
\hline Arg/SDMA & $26.6(7.7)$ & $24.7(7.0)$ & $26.6(7.8)$ & $0.041^{* *}$ \\
\hline
\end{tabular}

* The values are given as median (IQR) and compared by the Kruskal-Wallis test. ${ }^{*}$ The values are given as mean

(SD) and compared by ANOVA.

\subsection{Arginine and Metabolite Concentrations According to Gender}

The mean arginine concentrations were higher in the amniotic fluid from female (40.8 (SD 10.6) $\mu \mathrm{mol} / \mathrm{L}$ ) compared to male fetuses (37.4 (SD 11.2) $\mu \mathrm{mol} / \mathrm{L}, p=0.003$ ), whereas no differences were seen for ADMA $(p=0.16)$ and SDMA $(p=0.30)$ according to gender.

The mean Arg/ADMA ratio was higher in the amniotic fluid from female (15.3 (SD 3.3)) compared to male fetuses (14.4 (SD 3.5), $p=0.007$ ), whereas no significant difference according to gender was seen in the Arg/SDMA ratio $(p=0.07)$.

\subsection{Arginine and Metabolite Concentrations as Determinants for Birth Weight, Length, and Head Circumference}

Birth weight was positively correlated to arginine $(r=0.23, p<0.001)$ and ADMA $(r=0.25$, $p<0.001)$, weakly correlated to SDMA $(r=0.17, p=0.001)$, and not correlated to Arg/ADMA ( $p=$ $0.26)$ and Arg/SDMA ratios $(p=0.21)$ by Spearman correlation. Positive correlations were also seen for birth length versus arginine $(r=0.14, p=0.02)$, ADMA $(r=0.18, p=0.002)$, and SDMA $(r=0.12$, 
$p=0.04)$, but not versus Arg/ADMA $(p=0.97)$ or Arg/SDMA $(p=0.66)$ ratios. Head circumference was positively correlated only to arginine $(r=0.17, p=0.01)$.

Amniotic fluid arginine was the strongest predictor for birth weight, length, and head circumference in multiple linear regression models which additionally included gender, gestational week, and storage period (Table 3). ADMA was a strong predictor for birth weight and length, SDMA for birth weight, while the ratios Arg/ADMA and Arg/SDMA were significant predictors only for head circumference (Table 3).

Table 3. Arginine and metabolites in the amniotic fluid as determinants of birth weight, length, and head circumference by multiple linear regression.

\begin{tabular}{|c|c|c|c|c|c|c|c|c|c|}
\hline \multirow{3}{*}{$\begin{array}{l}\text { Independent } \\
\text { Variables * }\end{array}$} & \multicolumn{9}{|c|}{ Dependent Variables } \\
\hline & \multicolumn{3}{|c|}{$\begin{array}{l}\text { Birth Weight (g) } \\
\quad(n=363)\end{array}$} & \multicolumn{3}{|c|}{$\begin{array}{l}\text { Birth Length }(\mathrm{cm}) \\
\quad(n=275)\end{array}$} & \multicolumn{3}{|c|}{$\begin{array}{l}\text { Head Circumference }(\mathrm{cm}) \\
(n=239)\end{array}$} \\
\hline & B & $95 \% \mathrm{CI}$ & $p$-Value & B & $95 \% \mathrm{CI}$ & $p$-Value & B & $95 \% \mathrm{CI}$ & $p$-Value \\
\hline Arginine & 116 & $(69,174)$ & $<0.001$ & 0.4 & $(0.1,0.7)$ & 0.01 & 0.3 & $(0.1,0.4)$ & 0.003 \\
\hline ADMA & 99 & $(50,147)$ & $<0.001$ & 0.3 & $(0.1,0.6)$ & 0.02 & 0.2 & $(-0.03,0.3)$ & 0.094 \\
\hline SDMA & 68 & $(19,116)$ & 0.006 & 0.3 & $(0.0,0.6)$ & 0.06 & 0.1 & $(-0.1,0.3)$ & 0.24 \\
\hline Arg/ADMA & 30 & $(-18,79)$ & 0.22 & 0.04 & $(-0.2,0.3)$ & 0.79 & 0.2 & $(0.0,0.3)$ & 0.05 \\
\hline Arg/SDMA & 57 & $(9,105)$ & 0.02 & 0.07 & $(-0.2,0.4)$ & 0.64 & 0.2 & $(0.01,0.3)$ & 0.03 \\
\hline
\end{tabular}

* Separate models were used for each amino acid and for the ratios. Each model additionally contained gender, gestational age, and storage period. Amino acids and ratios were categorized as quartiles.

Birth weight $(p<0.001)$, length $(p=0.19)$, and head circumference $(p=0.05)$ increased with increasing arginine concentrations in the amniotic fluid (Figure 1).

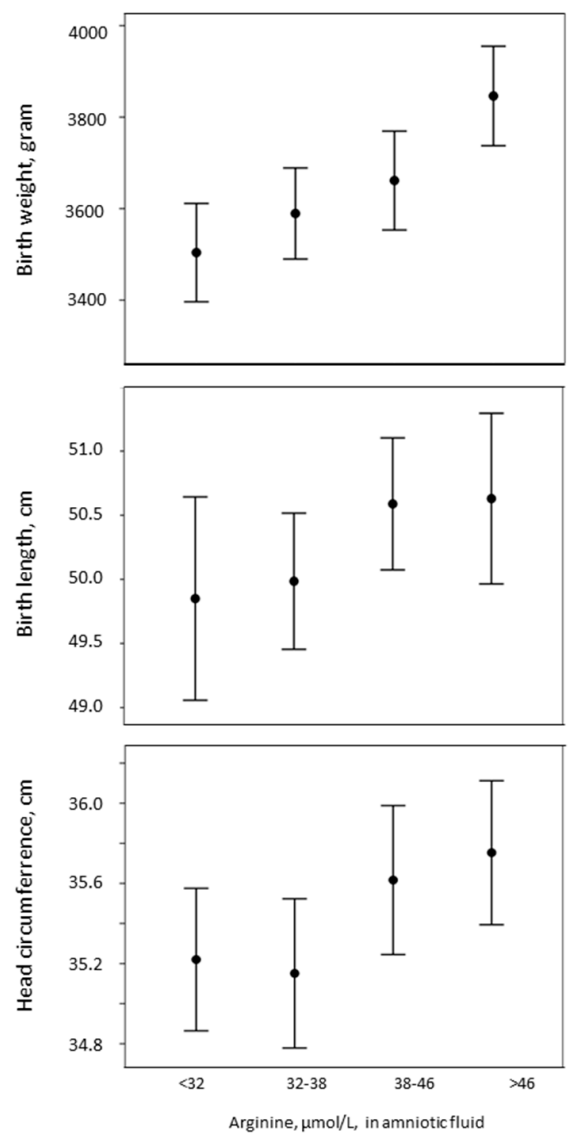

Figure 1. Changes in birth weight, length, and head circumference with respect to amniotic fluid arginine concentrations, in quartiles. 
A dose-response relationship between birth weight and arginine, ADMA, and SDMA was visualized by GAM curves corrected for gender, gestational week, and storage time (Figure 2).
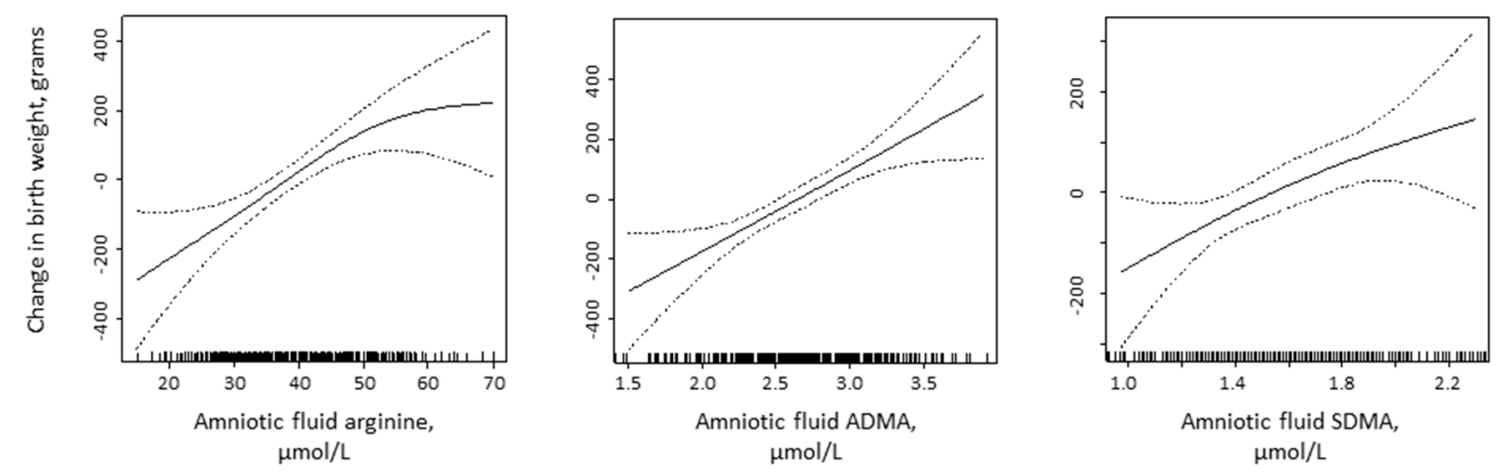

Figure 2. Changes in birth weight in relation to arginine, ADMA, and SDMA concentrations in the amniotic fluid from gestational weeks $13-15$ by generalized additive models (GAM).

\section{Discussion}

Arginine, ADMA, and SDMA decreased in the amniotic fluid from gestational weeks 13-15. Arginine was higher in the amniotic fluid from female compared to male fetuses. Arginine was the strongest predictor for birth weight, length, and head circumference, followed by ADMA for birth weight and length and SDMA for birth weight, while the ratios Arg/ADMA and Arg/SDMA were only related to head circumference.

\subsection{Strength and Limitations}

The amniotic fluid samples were taken for routine prenatal diagnostic purposes and stored at a nonoptimal temperature (minus $20^{\circ} \mathrm{C}$ ) for $1-4$ years before analysis, which may influence arginine and metabolite concentrations. However, under these conditions, ADMA and SDMA are stable in both serum and plasma, whereas arginine may increase about $2.5 \%$ per year in serum (but not in plasma), a change that has been attributed to proteolysis [16]. However, there was no difference in the storage time in relation to the gestational week at sampling.

As this study was done on anonymous samples, the information on the maternal status was limited, and factors known to be related to birth outcome, like prepregnancy body mass index, parity, smoking, and socioeconomic status, were not available [17]. However, all samples included in the study had a documented normal outcome.

\subsection{Gender Differences}

We found higher concentrations of arginine, no difference in ADMA and SDMA, and a higher Arg/ADMA ratio in the amniotic fluid in pregnancies from female compared to male fetuses. The same gender difference, with higher plasma arginine concentrations in females, was observed in mice [18].

Amniotic fluid testosterone concentration is reported to be higher in male than female fetuses at gestational week 15 [19]. As testosterone is known to stimulate arginase [20], this may contribute to the observed lower arginine concentrations observed in the amniotic fluid from male fetuses [18].

\subsection{Amniotic Fluid Arginine Levels during Pregnancy}

Published data on amniotic fluid arginine concentrations are scarce, and data on ADMA and SDMA are missing. We found that arginine concentrations decreased from gestational week 13 to 15 , and the mean concentration obtained in week $15(36.0$ (SD 8.3) $\mu \mathrm{mol} / \mathrm{L})$ resembles published data from one study on amniotic fluid from pregnancy week 15, mean 34.8 (SD 12) $\mu \mathrm{mol} / \mathrm{L}$ [21]. 


\subsection{Arginine, ADMA, and SDMA in the Amniotic Fluid Compared to Maternal Plasma and Cord Blood}

Amniotic fluid volume increases from about $25 \mathrm{~mL}$ at 10 weeks to about $400 \mathrm{~mL}$ at 20 weeks. Before keratinization of the fetal skin, amino acids and other nutrients diffuse into the amniotic fluid from the placenta through the placental membranes, and from the fetal circulation through the fetal skin, and the composition of the amniotic fluid is considered to reflect that of fetal plasma [1].

However, the concentrations of arginine, ADMA, and SDMA that we observed in the amniotic fluid differed substantially from the published concentrations in maternal plasma in early pregnancy and in cord blood at term. The mean amniotic fluid arginine concentration at week 15 (36.0 (SD 8.3) $\mu \mathrm{mol} / \mathrm{L}$ ) was less than half $(42 \%)$ of the one that was reported in maternal plasma at pregnancy week 16 (estimated mean 85.5 (SE 4.6) $\mu \mathrm{mol} / \mathrm{L}$ ) [22], and in the umbilical cord vein at term (median 85.3 (IQR 69.7-95.0) $\mu \mathrm{mol} / \mathrm{L}[22,23]$. In pregnancy, there is a high demand for arginine for the production of polyamines and NO [4], so the lower arginine levels in the amniotic fluid may reflect arginine consumption by the placenta and the fetus. The placenta lacks arginase, a strategy which is suggested to maximize the availability of arginine in the systemic circulation from mother to fetus [4].

The mean ADMA concentration in the amniotic fluid at week 15 (2.28 (SD 0.38) $\mu \mathrm{mol} / \mathrm{L}$ ) was substantially higher (585\%) compared to maternal plasma ADMA concentrations at pregnancy week 16 (estimated mean 0.39 (SE 0.02) $\mu \mathrm{mol} / \mathrm{L}$ ) [22], and substantially higher (178\%) compared to the umbilical cord vein at term (median 1.28 (IQR 1.18-1.38) $\mu \mathrm{mol} / \mathrm{L}$ ) [23]. Our mean SDMA in the amniotic fluid at week $15(1.41$ (SD 0.31) $\mu \mathrm{mol} / \mathrm{L})$ was also higher (353\%) than in maternal plasma (estimated mean 0.40 (SE 0.02) $\mu \mathrm{mol} / \mathrm{L})$ [22], but slightly lower (83\%) than in the umbilical cord vein at term (median 1.69 (IQR 1.48-2.01) $\mu \mathrm{mol} / \mathrm{L})$ [23].

It has been suggested that the placenta is the primary source of ADMA present in fetal circulation and that the observed high ADMA concentration may be a compensatory mechanism to stabilize the high NO concentrations in the fetoplacental unit [23].

The amniotic fluid Arg/ADMA ratio at week 15 (16.1 (SD 4.0) was only 7\% of reported maternal plasma ratio in pregnancy week 16 (estimated mean 226.8, (SE 12.4)) [22], and 24\% of reported median umbilical cord vein ratio at term (66.0 (IQR 56.3-72.9) [23].

\subsection{Arginine, ADMA, and SDMA as Determinants for Fetal Growth}

Arginine was the strongest predictor for birth weight, length, and head circumference, followed by gender. The metabolites ADMA and SDMA were weakly related to birth weight and length, while the ratios Arg/ADMA and Arg/SDMA were weakly related to head circumference.

Published data on the relation between birth weight and amniotic fluid concentrations of arginine, ADMA, and SDMA are missing. No significant correlations between circulating arginine, ADMA, SDMA levels, and birth weight were seen in 130 neonates born premature ( $<30$ gestational week) with a very low birth weight (<1500 grams) [24]. However, maternal plasma arginine concentrations were found to be lower in pregnancies complicated by fetal growth restriction $[13,14]$.

Our findings reflect the importance of arginine in pregnancy, derived from its diverse functions, both as a constituent of proteins and as a precursor for polyamines and NO, which make it essential for growth and angiogenesis. An adequate concentration of arginine was shown to be crucial for placentation, utero-placental blood flow and transfer of nutrients to the fetus, embryogenesis, and fetal growth and development [25]. Arginine concentrations markedly increase in the uterine lumen during the peri-implantation period of pregnancy [26,27], and arginine is also abundant in the conceptus [28]. The placental synthesis of both $\mathrm{NO}$ and polyamines in animal studies was found to be highest during early gestation when placental growth is most rapid $[5,29,30]$. Whether this is the case for humans is unknown.

Both animal and human studies have shown enhanced placental-fetal development and growth after arginine supplementation in pregnancy [31-33]. The human studies were done in pregnancies with a diagnosis of gestational hypertension [31] or intrauterine growth retardation [32,33]. The supplementation was initiated in middle or late pregnancy and was associated with increased birth weight [32,33], reductions in diastolic blood pressure, and prolonged pregnancy [31]. 


\section{Conclusions}

Arginine in the amniotic fluid from gestational weeks 13 to 15 was found to be a strong predictor of birth weight, length, and head circumference, while ADMA was a predictor for birth weight and length and SDMA only for birth weight.

Our findings reflect the importance of arginine metabolism in pregnancy, because of its diverse functions, both as a constituent of proteins and as a precursor for polyamines and NO, which make it essential for placentation, angiogenesis, and growth. Whether an improved maternal arginine status in early pregnancy may enhance fetal growth, should be evaluated in an intervention study.

Acknowledgments: We thank the laboratory staff at Bevital AS, Bergen, Norway, for analyzing the blood samples.

Author Contributions: A. Bjørke-Jenssen analyzed the data and wrote the paper, P. M. Ueland was responsible for the laboratory analyses and wrote the paper. A.-L. Bjørke-Monsen conceived, designed, and performed the study, analyzed the data and wrote the paper. All authors approved the final version.

Conflicts of Interest: The authors have no financial relationships to disclose and no conflicts of interest relevant to this article. The study was supported by grants from the Foundation to promote research into functional vitamin B12 deficiency. The sponsor of the study had no role in the study design, data collection, data analysis, data interpretation, writing of the report, or in the decision to submit the paper for publication. The corresponding author had full access to all the data in the study and had the final responsibility for the decision to submit for publication.

\section{References}

1. Underwood, M.A.; Gilbert, W.M.; Sherman, M.P. Amniotic fluid: Not just fetal urine anymore. J. Perinatol. 2005, 25, 341-348. [CrossRef] [PubMed]

2. Bazer, F.W.; Johnson, G.A.; Wu, G. Amino acids and conceptus development during the peri-implantation period of pregnancy. Adv. Exp. Med. Biol. 2015, 843, 23-52. [PubMed]

3. Leese, H.J.; Brison, D.R. Cell Signaling during Mammalian Early Embryo Development; Springer: New York, NY, USA, 2015.

4. Wu, G.; Bazer, F.W.; Davis, T.A.; Kim, S.W.; Li, P.; Marc Rhoads, J.; Carey Satterfield, M.; Smith, S.B.; Spencer, T.E.; Yin, Y. Arginine metabolism and nutrition in growth, health and disease. Amino Acids 2009, 37, 153-168. [CrossRef] [PubMed]

5. Wu, G.; Bazer, F.W.; Hu, J.; Johnson, G.A.; Spencer, T.E. Polyamine synthesis from proline in the developing porcine placenta. Biol. Reprod. 2005, 72, 842-850. [CrossRef] [PubMed]

6. Mandal, S.; Mandal, A.; Johansson, H.E.; Orjalo, A.V.; Park, M.H. Depletion of cellular polyamines, spermidine and spermine, causes a total arrest in translation and growth in mammalian cells. Proc. Natl. Acad. Sci. USA 2013, 110, 2169-2174. [CrossRef] [PubMed]

7. Bode-Boger, S.M.; Scalera, F.; Ignarro, L.J. The L-arginine paradox: Importance of the L-arginine/ asymmetrical dimethylarginine ratio. Pharmacol. Ther. 2007, 114, 295-306. [CrossRef] [PubMed]

8. Boger, R.H.; Sullivan, L.M.; Schwedhelm, E.; Wang, T.J.; Maas, R.; Benjamin, E.J.; Schulze, F.; Xanthakis, V.; Benndorf, R.A.; Vasan, R.S. Plasma asymmetric dimethylarginine and incidence of cardiovascular disease and death in the community. Circulation 2009, 119, 1592-1600. [CrossRef] [PubMed]

9. Sladek, S.M.; Magness, R.R.; Conrad, K.P. Nitric oxide and pregnancy. Am. J. Physiol. 1997, 272, R441-R463. [PubMed]

10. Zhou, Y.; Fisher, S.J.; Janatpour, M.; Genbacev, O.; Dejana, E.; Wheelock, M.; Damsky, C.H. Human cytotrophoblasts adopt a vascular phenotype as they differentiate. A strategy for successful endovascular invasion? J. Clin. Investig. 1997, 99, 2139-2151. [CrossRef] [PubMed]

11. Visek, W.J. Arginine needs, physiological state and usual diets. A reevaluation. J. Nutr. 1986, 116, 36-46. [PubMed]

12. Morris, N.H.; Eaton, B.M.; Dekker, G. Nitric oxide, the endothelium, pregnancy and pre-eclampsia. Int. J. Obstet. Gynaecol. 1996, 103, 4-15. [CrossRef]

13. Bavoux, F.; Georges, P.; Bouy, M.; Leroy, B. Growth retardation and amino acids. Analysis of maternal plasma and amniotic fluid. J. Gynecol. Obstet. Biol. Reprod. 1977, 6, 931-940.

14. Yu, K. Umbilical and maternal amino acid concentrations in appropriate and small for gestational age infants. Zhonghua Yi Xue Za Zhi 1992, 72, 453-455, 508. [PubMed] 
15. Midttun, O.; Kvalheim, G.; Ueland, P.M. High-throughput, low-volume, multianalyte quantification of plasma metabolites related to one-carbon metabolism using HPLC-MS/MS. Anal. Bioanal. Chem. 2013, 405, 2009-2017. [CrossRef] [PubMed]

16. Hustad, S.; Eussen, S.; Midttun, O.; Ulvik, A.; van de Kant, P.M.; Morkrid, L.; Gislefoss, R.; Ueland, P.M. Kinetic modeling of storage effects on biomarkers related to B vitamin status and one-carbon metabolism. Clin. Chem. 2012, 58, 402-410. [CrossRef] [PubMed]

17. Orskou, J.; Henriksen, T.B.; Kesmodel, U.; Secher, N.J. Maternal characteristics and lifestyle factors and the risk of delivering high birth weight infants. Obstet. Gynecol. 2003, 102, 115-120. [PubMed]

18. Luiking, Y.C.; Hallemeesch, M.M.; Vissers, Y.L.; Lamers, W.H.; Deutz, N.E. In vivo whole body and organ arginine metabolism during endotoxemia (sepsis) is dependent on mouse strain and gender. J. Nutr. 2004, 134, 2768S-2774S. [PubMed]

19. Rodeck, C.H.; Gill, D.; Rosenberg, D.A.; Collins, W.P. Testosterone levels in midtrimester maternal and fetal plasma and amniotic fluid. Prenat. Diagn. 1985, 5, 175-181. [CrossRef] [PubMed]

20. Kumar, A.N.; Kalyankar, G.D. Effect of steroid hormones on age dependent changes in rat arginase isoenzymes. Exp. Gerontol. 1984, 19, 191-198. [CrossRef]

21. Lopez Ramon, Y.C.C.; Ocampo Martinez, R.; Couceiro Naveira, E.; Martinez, M. Amino acids in amniotic fluid in the 15th-16th weeks of gestation and preterm labor. J. Matern. Fetal Neonatal Med. 2007, 20, 225-231. [CrossRef] [PubMed]

22. Rijvers, C.A.; Marzano, S.; Winkens, B.; Bakker, J.A.; Kroon, A.A.; Spaanderman, M.E.; Peeters, L.L. Early-pregnancy asymmetric dimethylarginine (ADMA) levels in women prone to develop recurrent hypertension. Pregnancy Hypertens. 2013, 3, 118-123. [CrossRef] [PubMed]

23. Braekke, K.; Ueland, P.M.; Harsem, N.K.; Staff, A.C. Asymmetric dimethylarginine in the maternal and fetal circulation in preeclampsia. Pediatr. Res. 2009, 66, 411-415. [CrossRef] [PubMed]

24. Moonen, R.M.; Huizing, M.J.; Cavallaro, G.; Gonzalez-Luis, G.E.; Bas-Suarez, P.; Bakker, J.A.; Villamor, E. Plasma levels of dimethylarginines in preterm very low birth weight neonates: Its relation with perinatal factors and short-term outcome. Int. J. Mol. Sci. 2014, 16, 19-39. [CrossRef] [PubMed]

25. Wu, G.; Bazer, F.W.; Satterfield, M.C.; Li, X.; Wang, X.; Johnson, G.A.; Burghardt, R.C.; Dai, Z.; Wang, J.; $\mathrm{Wu}, \mathrm{Z}$. Impacts of arginine nutrition on embryonic and fetal development in mammals. Amino Acids 2013, 45, 241-256. [CrossRef] [PubMed]

26. Gao, H.; Wu, G.; Spencer, T.E.; Johnson, G.A.; Li, X.; Bazer, F.W. Select nutrients in the ovine uterine lumen. I. Amino acids, glucose, and ions in uterine lumenal flushings of cyclic and pregnant ewes. Biol. Reprod. 2009, 80, 86-93. [CrossRef] [PubMed]

27. Kim, J.; Song, G.; Wu, G.; Gao, H.; Johnson, G.A.; Bazer, F.W. Arginine, leucine, and glutamine stimulate proliferation of porcine trophectoderm cells through the MTOR-RPS6K-RPS6-EIF4EBP1 signal transduction pathway. Biol. Reprod. 2013, 88, 1-9. [CrossRef] [PubMed]

28. Wu, G.; Wu, Z.; Dai, Z.; Yang, Y.; Wang, W.; Liu, C.; Wang, B.; Wang, J.; Yin, Y. Dietary requirements of "nutritionally non-essential amino acids" by animals and humans. Amino Acids 2013, 44, 1107-1113. [CrossRef] [PubMed]

29. Kwon, H.; Wu, G.; Meininger, C.J.; Bazer, F.W.; Spencer, T.E. Developmental changes in nitric oxide synthesis in the ovine placenta. Biol. Reprod. 2004, 70, 679-686. [CrossRef] [PubMed]

30. Wu, G.; Imhoff-Kunsch, B.; Girard, A.W. Biological mechanisms for nutritional regulation of maternal health and fetal development. Paediatr. Perinat. Epidemiol. 2012, 26 (Suppl. S1), 4-26. [CrossRef] [PubMed]

31. Gui, S.; Jia, J.; Niu, X.; Bai, Y.; Zou, H.; Deng, J.; Zhou, R. Arginine supplementation for improving maternal and neonatal outcomes in hypertensive disorder of pregnancy: A systematic review. J. Renin Angiotensin Aldosterone Syst. 2014, 15, 88-96. [CrossRef] [PubMed]

32. Xiao, X.M.; Li, L.P. L-arginine treatment for asymmetric fetal growth restriction. Int. J. Gynaecol. Obstet. Obstet. 2005, 88, 15-18. [CrossRef] [PubMed]

33. Shen, S.F.; Hua, C.H. Effect of L-arginine on the expression of Bcl-2 and BAX in the placenta of fetal growth restriction. J. Matern. Fetal Neonatal Med. 2011, 24, 822-826. [CrossRef] [PubMed]

(C) 2017 by the authors. Licensee MDPI, Basel, Switzerland. This article is an open access article distributed under the terms and conditions of the Creative Commons Attribution (CC BY) license (http:/ / creativecommons.org/licenses/by/4.0/). 